\title{
Increased neutrophil-to-lymphocyte ratio predicts the development of post-stroke infections in patients with acute ischemic stroke
}

\author{
Lanying He ${ }^{1}$, Jian Wang ${ }^{1 *}$, Feng Wang ${ }^{1}$, Lili Zhang ${ }^{1}$, Lijuan Zhang ${ }^{2}$ and Wang Zhao ${ }^{3}$
}

\begin{abstract}
Background: Infections could increase the risk of poor outcome in patients with acute ischemic stroke (AIS). The peripheral neutrophil-to-lymphocyte ratio (NLR) is an important indicator of inflammation. The purpose of our study was to investigate the association increased NLR with post stroke infections (PSI) in AIS.

Methods: In this study, we included 606 consecutive patients with AIS within $24 \mathrm{~h}$. The NLR was calculated by dividing absolute neutrophil counts by absolute lymphocyte counts. Receiver operating characteristic (ROC) curve was performed to identify the optimal cut point of NLR for PSI. The relationship between NLR and PSI was analyzed by multivariable analysis.

Results: We assessed 606 consecutive patients with AIS. ROC curve analysis showed that the optimal cut point of NLR for PSI was NLR $\geq 5.79$. Compared with no PSI, patients with PSI have higher NLR, older age, higher NIHSS, higher $P C T$, higher percentage of nasogastric tube feeding and indwelling urinary catheter $(P<0.05)$. Multivariable analysis showed that NLR $\geq 5.79$ [adjusted odds ratio (aOR),4.52; 95\% confidence interval (Cl),3.02-6.76; $P<0.001$ ], older age $(a O R, 1.03 ; 95 \% \mathrm{Cl}, 1.00-1.05 ; P=0.009)$, higher admission NIHSS $(a O R, 1.13 ; 95 \% \mathrm{Cl}, 1.07-1.18 ; P<0.001)$, indwelling urinary catheter (aOR1.83; 95\%Cl, 1.08-3.10; $P=0.026]$, and nasogastric tube feeding (aOR2.52; 95\%Cl, 1.38-4.59; $P=0.003$ ) were associated with increased risk of PSI.
\end{abstract}

Conclusions: Higher NLR can predict PSI in AIS patients. The NLR may help to select high-risk patients to start intervention in time.

Keywords: Acute ischemic stroke, Neutrophil-to-lymphocyte ratio, Post stroke infections

\section{Background}

Infections are the most common complication following acute ischemic stroke (AIS) contributing to unfavorable functional outcome and mortality [1-3]. Post-stroke infection (PSI) included stroke-associated pneumonia (SAP), urinary tract infection (UTI), and other

\footnotetext{
* Correspondence: 383376877@qq.com

'Department of Neurology, The Second People's Hospital of Chengdu, Chengdu 610021, People's Republic of China

Full list of author information is available at the end of the article
}

localization's infection, occurring in up to about $30-40 \%$ $[4,5]$. Older age, stroke severity, oropharyngeal.

dysphagia, orotracheal intubation are risk factors for PSI [6, 7]. Evidence cumulates that immunomodulation after AIS has been associated with an increased the susceptibility to PSI [8-10].

The neutrophil-to-lymphocyte ratio (NLR) is a commonly used indicator of systemic inflammation and infection. As a reflection of innate and adaptive immune responses, NLR has been widely studied due to its easy

(c) The Author(s). 2020 Open Access This article is licensed under a Creative Commons Attribution 4.0 International License, which permits use, sharing, adaptation, distribution and reproduction in any medium or format, as long as you give appropriate credit to the original author(s) and the source, provide a link to the Creative Commons licence, and indicate if changes were made. The images or other third party material in this article are included in the article's Creative Commons licence, unless indicated otherwise in a credit line to the material. If material is not included in the article's Creative Commons licence and your intended use is not permitted by statutory regulation or exceeds the permitted use, you will need to obtain permission directly from the copyright holder. To view a copy of this licence, visit http://creativecommons.org/licenses/by/4.0/. The Creative Commons Public Domain Dedication waiver (http://creativecommons.org/publicdomain/zero/1.0/) applies to the data made available in this article, unless otherwise stated in a credit line to the data. 
obtain from peripheral blood. Increased NLR level with increased neutrophils and decreased lymphocyte, suggesting an imbalanced interaction between strokerelated central and peripheral inflammation. It has been studied as a predictor of bacterial infection, showing better predictive value than traditional markers of inflammation [11-14].

In the last decade, the importance of NLR in acute stroke has aroused the interest of many scholars. Higher NLR may be an independent predictor for poor outcome after AIS $[15,16]$. Recent studies had shown that even in AIS patients with thrombolytic or thrombectomy, high NLR increased risks of early neurological deterioration, parenchymal hemorrhage, 3-month poor outcome, and mortality, especially in patients with diabetes [17-20]. A retrospective study also shown that NLR on admission was associated with increased risks of 30-day mortality and 90-day poor outcome in patients with critically ill stroke [21]. The recent study shown that NLR predicted SAP in patients with AIS [22, 23].

At present, there are few studies on the relationship between NLR and PSI. Hence, we assembled a cohort of patients with AIS from three centers to investigate whether elevated NLR value was associated the occurrence of PSI after AIS.

\section{Methods}

\section{Study population}

This study was a multicenter prospective study conducted in three medical centers: The Second People's Hospital of Chengdu, Yongchuan Hospital of Chongqing Medical University, Nuclear Industry 416 Hospital. The patients with AIS were admitted within $24 \mathrm{~h}$ of the onset symptom between March 2014 and December 2017. AIS were evaluated by $\mathrm{CT}$ or diffusion-weighted imaging (DWI) using Siemens Magnetom Avanto 1.5 Tesla (Siemens Medical Solutions, Erlangen, Germany). The initial severity of stroke was assessed by National Institutes of Health Stroke Scale (NIHSS). Stroke etiology was classified according to the modified Trial of ORG 10172 in Acute Stroke Treatment (TOAST) criteria in three medical centers.

\section{Inclusion and exclusion criteria}

Patients were enrolled only if they fulfilled the following criteria: 1. Age $\geq 18$ years; 2. Admission for first-ever acute ischemic stroke within $24 \mathrm{~h} ; 3$. Evidence for ischemic lesions is consistent with clinical presentation; 4. All patients received standard therapy (including antiplatelet, statins, blood pressure control, or intravenous thrombolysis or/and endovascular treatment). The exclusion criteria were the following: 1 . Oning infection at admission; 2. a history of previous stroke; 3 . Cerebral hemorrhage, hypoxia (arterial oxyhemoglobin saturation $<90 \%$ ).

\section{Clinical assessment and definition of PSI}

We collected the characteristics and vascular risk factors of the patients. Dysphagia was assessed using noninstrumented swallowing tests at admission. The patients were managed with modifications based on swallowing test. Blood cell counts, lipid, and glucose were obtained within $24 \mathrm{~h}$. The neutrophil count divided by the lymphocyte count yielded the NLR.

Infections included SAP, UTI, and other localization's infections. Within 7 days of admission, symptoms and signs of infection were monitored, along with key indicators including white blood cell count, procalcitonin (PCT), urine screening, body temperature at least 3 times a day. UTI was diagnosed if the WBC count was elevated and nitrite positive during urine screening, accompanied by leukocytosis, PCT $>50 \mathrm{mg} / \mathrm{dl}$, and urine culture positive.

SAP was diagnosed in according with the modified Centers and Prevention critaria of hospital-acquired, based on clinical and laboratory parameters of respiratory tract infection, and was confirmed by both chest Xray and $\mathrm{CT}$. Infection can also be diagnosed if the body temperature exceeds $38.0^{\circ} \mathrm{C}$ and at least two tests show additional leukocytosis and positive blood culture, but no determined focus. PSI was diagnosed by two experienced neurologists who were blinded to other clinical and laboratory findings during the first 7 days of hospitalization.

\section{Statistical analysis}

First, patients were classified into no PSI and PSI groups. The data are presented as median values (interquartile range $[\mathrm{IQR}]$ ), numbers (\%), or mean values ( \pm standard deviation). To identify differences between subgroups, the Pearson $\chi^{2}$ test was used for categorical variables. Distributions of continuous variables were determined by the Kolmogorov-Smirnov test, while Mann-Whitney two sample test was applied in case of non-normal distributions. Second, Receiver operating characteristic (ROC) curve analysis was used to evaluate sensitivity, specificity and to determine the optimal cut point of NLR for PSI. Third, we then performed logistic regressions analyses to determine the association between NLR and PSI, adjusting for all confounders (age, baseline NIHSS score, sex, BMI, hypertension, current smoking, current alcohol drinking, diabetes, hyperlipidemia, thrombolytic therapy, thrombectomy, thrombolytic therapy + thrombectomy, family history of stroke, etiological classification, nasogastric tube feeding, indwelling urinary catheter, and medications use). Results were expressed as adjusted odds ratios (OR) with the 
corresponding 95\% confidence interval (CI). The data were analyzed using SPSS software (SPASS 22.0). $P$ values $<0.05$ were considered as statistically significant.

\section{Results}

\section{Characteristics of the study subjects}

Six hundred six patients with AIS met the inclusion criteria. The mean age was $66.72 \pm 10.35$ years $(40-96$ years), comprised $48.84 \%$ (296) men. In the study population, 391 patients had a history of hypertension, 211 had a history of diabetes, 334 had a history of hyperlipidemia, 163 patients current Smoking,183patients current alcohol drinking. The median NIHSS score at admission was 9 points. 104(17.16\%) of patients underwent intravenous thrombolysis and 33(5.45\%) underwent thrombectomy.9(1.49\%) underwent intravenous thrombolysis add thrombectomy.194 (32.01\%) patients developed an infection within first 7 days after admission.

\section{Evaluation of the prognostic value of NLR for PSI}

ROC curve analysis showed high accuracy for NLR to predict PSI with AUC of 0.72 (95\% CI 0.68 to 0.76) (Fig. 1). Using a cut off value for NLR $\geq 5.79$, the sensitivity was $65.98 \%$, and the specificity was $70.63 \%$, providing a positive predictive value (PPV) for PSI of $51.40 \%$, and providing a negative predictive value (NPV) for PSI of $81.51 \%$

\section{Univariable models for predictors of PSI}

194 (32.01\%) patients had PSI with 7 days after AIS. One hundred twenty patients had SAP, 64 had UTI,10 patients had infections with other localization. Patients with NLR $\geq 5.79$ experienced more SAP [33,73\%(84/249) versus $10.08 \%$ (36/357), $P<0.001]$ and UIT[15.67\% (39/

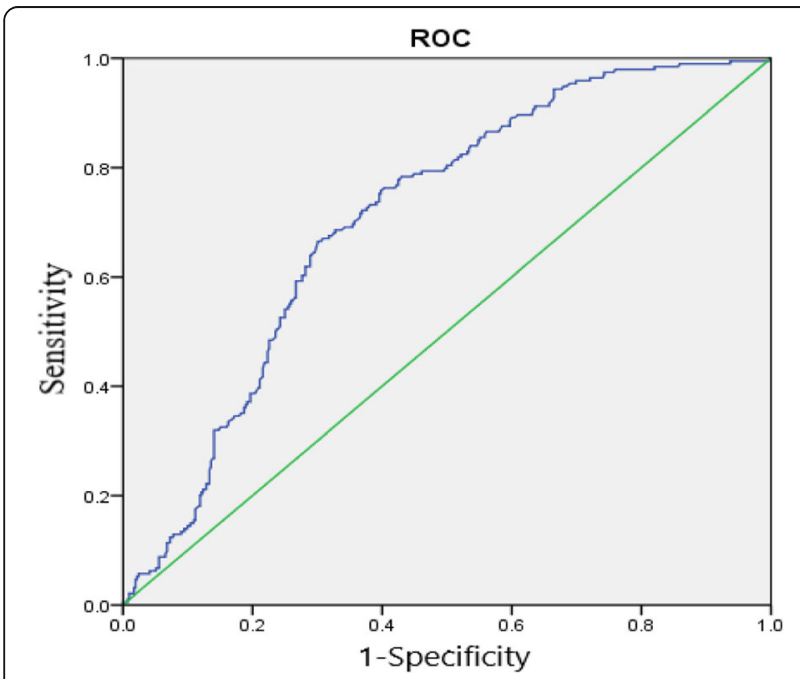

Fig. 1 Receiver operating characteristic curve analysis for NLR for prognostic value for PSI
249 ) versus $7.00 \%(25 / 357), P=0.001]$. Baseline characteristics of patients in the no PSI and PSI groups were compared (Table 1). At baseline, patients with PSI showed significantly older age $(68.59 \pm 10.72$ vs $65.85 \pm$ $10.06, \mathrm{P}=0.001)$, higher NIHSS [10(7-13) vs $8(6-11)$, $P<0.001]$, higher NLR[6.99(4.93-8.31) vs $4.25(2.92-$ 6.45), $P<0.001$ ], higher $\mathrm{PCT}(1.81 \pm 0.86$ vs $0.54 \pm 4.92$, $P<0.001)$, higher prevalence of indwelling urinary catheter (aOR1.83; 95\%CI, $1.08-3.10 ; P=0.026]$, and nasogastric tube feeding (aOR2.52; 95\%CI, 1.38-4.59; $P=$ $0.003)$ than patients with no PSI. Compared with patients no PSI, those with PSI had higher prevalence of NLR $\geq 5.79$ (65.78\% vs $29.37 \%, P<0.001)$.

\section{Multivariable models on the association between NLR $\geq$ 5.79 and PSI}

In unadjusted models, there was an association between $\mathrm{NLR} \geq 5.79$ and PSI group (OR,4.66;95\%CI, 3.24-6.72, $P<0.001)$. In the multivariable logistic regression model after adjustment for age, baseline NIHSS score, sex, BMI, hypertension, current smoking, current alcohol drinking, diabetes, hyperlipidemia, thrombolytic therapy, thrombectomy, thrombolytic therapy+Thrombectomy, family history of stroke, etiological classification, nasogastric tube feeding, indwelling urinary catheter, and medications use, NLR $\geq 5.79$ (aOR 4.52, 95\% CI 3.026.76, $P<0.001$ ), older age (aOR 1.03, 95\% CI 1.00-1.05, $P=0.009$ ), admission NIHSS (aOR 1.13, 95\% CI 1.07$1.18, P<0.001$ ), indwelling urinary catheter (aOR 1.83, 95\% CI 1.08-3.10, $p=0.026$ ), and nasogastric tube feeding ( $\mathrm{aOR} 2.52$, 95\% CI 1.38-4.59, $p=0.003$ ) were independently associated with increased risk of PSI (Table 2).

\section{Discussion}

Stroke is the most common disabling and fatal disease in adults. More than $40 \%$ surviving stroke patients have neurological deficit symptoms and need to be cared for [24]. The factors that affect the prognosis of the patients are the severity of stroke and old age. In addition, infection has a negative effect on the outcome [22, 25, 26], which plays an important role in extending hospital stay, worsening of neurological outcome, developing more serious complications and death [26]. In this study, we found that $32.01 \%$ of patients had infection within 7 days after AIS, which was consistent with previous studies [27, 28].

NLR may reliably predict inflammatory response, which represents the information of innate immune system and adaptive immune system. NLR is easy to obtain in clinical practice, it is cost-effective. NLR increases with the progression of some diseases, especially in inflammatory diseases, and this increase is consistent with the development of some diseases. A large number of 
Table 1 Comparison of baseline characteristics between patients with no PSI and PSI groups

\begin{tabular}{|c|c|c|c|c|}
\hline & no PSI group (412) & PSI group (194) & $\mathrm{OR}(95 \% \mathrm{Cl})$ & $P^{*}$ \\
\hline Age, y (Mean SD) & $65.85 \pm 10.06$ & $68.59 \pm 10.72$ & & 0.001 \\
\hline NIHSS score, median (IQR) & $8(6-11)$ & 10(7-13) & & $<0.001$ \\
\hline NLR, median (IQR) & $4.25(2.92-6.45)$ & $6.99(4.93-8.31)$ & & $<0.001$ \\
\hline Procalcitonin, $\mu \mathrm{g} / \mathrm{l}$ (Mean SD) & $0.54 \pm 4.92$ & $1.81 \pm 0.86$ & & $<0.001$ \\
\hline $\mathrm{NLR} \geq 5.79, \mathrm{n}(\%)$ & $121(29.37)$ & $128(65.78)$ & $4.66(3.24-6.72)$ & $<0.001$ \\
\hline Females,n(\%) & $220(53.40)$ & $90(46.39)$ & $0.73(0.52-1.03)$ & 0.107 \\
\hline Men,n(\%) & 192(46.60) & $104(53.61)$ & $0.760 .54-1.06)$ & 0.107 \\
\hline $\mathrm{BMI} \geq 24$ kg/m, n(\%) & $117(28.40)$ & $62(31.96)$ & $0.79(0.56-1.13)$ & 0.192 \\
\hline Hypertension,n(\%) & $273(66.26)$ & $118(60.82)$ & $0.79(0.56-1.13)$ & 0.192 \\
\hline Current Smoking,n(\%) & 104(25.24) & $59(30.41)$ & $1.29(0.89-1.89)$ & 0.181 \\
\hline Current alcohol drinking,n(\%) & $122(29.61)$ & $61(31.44)$ & $1.09(0.75-1.58)$ & 0.647 \\
\hline Diabetes, n(\%) & 138(33.50) & $73(37.62)$ & $1.20(0.84-1.71)$ & 0.319 \\
\hline Hyperlipidemia,n(\%) & $237(57.52)$ & $97(50.00)$ & $0.74(0.52-1.04)$ & 0.082 \\
\hline Thrombolytic therapy, n(\%) & $68(16.50)$ & $36(18.56)$ & $1.15(0.74-1.80)$ & 0.532 \\
\hline Thrombectomy, n(\%) & $25(6.07)$ & $8(4.12)$ & $0.67(0.30-1.50)$ & 0.325 \\
\hline Thrombolytic therapy+ Thrombectomy,n(\%) & $5(1.21)$ & $4(2.06)$ & $1.71(0.46-6.45)$ & 0.421 \\
\hline Family history of stroke,n(\%) & $84(20.39)$ & $38(19.59)$ & $0.95(0.62-1.50)$ & 0.819 \\
\hline \multicolumn{5}{|l|}{ Etiological classification } \\
\hline Large artery atherosclerosis,n(\%) & 137(33.25) & $70(36.08)$ & $1.13(0.79-1.62)$ & 0.493 \\
\hline Cardioembolism,n(\%) & $69(16.75)$ & $31(15.98)$ & $0.95(0.60-1.50)$ & 0.812 \\
\hline Lacunar, n(\%) & $122(29.61)$ & $62(31.96)$ & $1.12(0.77-1.61)$ & 0.558 \\
\hline Other known causes, n(\%) & $5(1.21)$ & $2(1.03)$ & $0.85(0.16-4.41)$ & 0.844 \\
\hline Undetermined, n(\%) & $82(19.90)$ & $30(15.46)$ & $0.74(0.47-1.16)$ & 0.189 \\
\hline Nasogastric tube feeding & $33(8.01)$ & $39(20.10$ & $2.89(1.75-4.76)$ & $<0.001$ \\
\hline Indwelling urinary catheter & $48(11.65)$ & $52(26.80)$ & $2.77(1.79-4.30)$ & $<0.001$ \\
\hline \multicolumn{5}{|l|}{ Medications use } \\
\hline Antiplatelet, n(\%) & 110(26.70) & $57(29.38)$ & $1.14(0.78-1.67)$ & 0.491 \\
\hline Antihypertensive, n(\%) & $220(53.40)$ & $99(51.03)$ & $0.91(0.65-1.28)$ & 0.586 \\
\hline Lipid-lowering medications, n(\%) & $182(44.17)$ & $78(40.21)$ & $0.85(0.60-1.20)$ & 0.357 \\
\hline
\end{tabular}

Bold indicates $P$-values less than 0.05 .

*Comparison between no PSI and PSI groups. The data are presented as median values (interquartile range [IQR]), numbers (\%), or mean values ( \pm standard deviation). Categorical variables are expressed as frequency (percent) for $P$ values Continuous variables are expressed as mean \pm standard deviation (SD). Baseline characteristics were compared between the 2 subgroups by univariate analysis using Pearson $\mathrm{X} 2$, distributions of continuous variables were determined by the Kolmogorov-Smirnov test, Mann-Whitney two sample test was applied in case of non-normal distributions

Table 2 Multivariable Models Showing Predictors of PSI

\begin{tabular}{lll}
\hline & $\mathrm{aOR}(95 \% \mathrm{Cl})$ & $P^{*}$ \\
\hline NLR $\geq 5.79$ & $4.52(3.02-6.76)$ & $<\mathbf{0 . 0 0 1}$ \\
Age & $1.03(1.00-1.05)$ & $\mathbf{0 . 0 0 9}$ \\
Admission NIHSS & $1.13(1.07-1.18)$ & $<\mathbf{0 . 0 0 1}$ \\
Indwelling urinary catheter & $1.83(1.08-3.10)$ & $\mathbf{0 . 0 2 6}$ \\
Nasogastric tube feeding & $2.52(1.38-4.59)$ & $\mathbf{0 . 0 0 3}$ \\
\hline
\end{tabular}

Bold indicates $P$-values less than 0.05 .

* Multivariable adjusted for age, baseline NIHSS score, sex, BMI, hypertension, current smoking, current alcohol drinking, diabetes, hyperlipidemia, thrombolytic therapy, thrombectomy, thrombolytic therapy+Thrombectomy, family history of stroke, etiological classification, nasogastric tube feeding, indwelling urinary catheter,and medications use studies have shown that higher NLR might be an independent predictor of clinical outcome in a variety of diseases, including malignant tumors, acute respiratory distress syndrome, fibrotic liver disease and cardiovascular diseases [29-32]. At present, it has been paid more attention in the research of neurovascular diseases [33-35]. Many studies have found that baseline NLR levels are higher in some AIS patients, with the increase of neutrophils and the decrease of lymphocytes, higher NLR indicated the imbalanced interaction between central and peripheral inflammation after AIS [36, 37]. Many studies shown that higher NLR on admission increased the risk of poor prognosis in AIS patients [16-20], but its diagnostic 
value for predicting infections after AIS has not been extensively investigated. In this study, we aimed to investigate the association between increased NLR and PSI in patients with AIS, and we found that a higher NLR was associated with increased risk of PSI in patients with AIS. The PSI group had a significantly higher NLR than that of the non-PSI group.

There are several underlined mechanisms for the relationship between the NLR and PSI. One explanation might be that the interaction of the brain's immune system is impaired after a stroke, leading to a stroke related immunosuppressive syndrome $[25,38]$. Ischemic stroke initiates local inflammatory immune response in brain tissue. Inflammatory factor such as interleukin-6, tumor necrosis factor- $\alpha$, interleukin- 1 , and matrix metalproteinase- 9 release from endothelium and brain parenchyma, which can further potentiate tissue injury, which disrupt of the brain-blood barrier (BBB). Inflammatory factors can enter the systemic circulation through the broken BBB $[39,40]$. Then, the systemic inflammatory response is changed through sympathetic pathway and hypothalamus pituitary adrenal axis [41], neutrophils are dedifferentiated and stimulated by growth factors [42], lymphocyte apoptosis, which increased the susceptibility of infection [43, 44]. Another explanation is that NLR is associated with stroke severity, and stroke severity is strong risk factor for infection $[9,45]$. In our study, ROC curve analysis showed that NLR $\geq 5.79$ was a useful marker for predicting infection. The AUC of 0.72 in PSI group further indicated that NLR was predictive of infection with high specificity, the result shown that the NLR $\geq 5.79$ group had a significantly higher NIHSS than that of the NLR<5.79 group $(9.73 \pm 4.76$ vs $8.94 \pm 4.19, P=0.038)$.

We observed that NLR $\geq 5.79$ was strong associated with increased risk of PSI within 7 days. The percentage of PSI in the NLR $\geq 5.79$ group was $51.41 \%(128 / 249)$, which was significantly higher than that in the NLR< 5.79 group $(18.49 \%, 66 / 357) \quad(P<0.001)$. After adjusting for fully confounders, in addition to age, NIHSS, indwelling urinary catheter and nasogastric tube feeding, we found a significant association of NLR $\geq 5.79$ with increased risk of PSI after AIS. These results suggested this association was independent of established risk factors, including age, baseline NIHSS score, sex, BMI, hypertension, current smoking, current alcohol drinking, diabetes, hyperlipidemia, thrombolytic therapy, thrombectomy, thrombolytic+thrombectomy therapy, family history of stroke, etiological classification, nasogastric tube feeding, indwelling urinary catheter, and medications use, and NLR detection could have prognostic value for infection among patients with AIS.

Some limitations of this study merit consideration. First, in this study, we relied on a single baseline NLR, we should monitor the changes of NLR dynamically, which might provide additional information on PSI. Second, due to incomplete data, we did not analyze the associated NLR with severity of infection, there also seemed to be an association between the NLR and infection severity. Third, we lack data on the possible influence of NLR on different infection (pneumonia, urinary tract infection, other location's infection). Fourth, even if we exclude infected patients before admission, we cannot exclude the bias of undiagnosed infections that occurred before admission. However, despite these limitations, our research has the advantage that its large sample size, its analysis, including models adjusting for a wide variety of confounders.

\section{Conclusions}

In conclusion, our study showed a positive correlation between increased NLR and PSI in patients with AIS. Early diagnosis of PSI is very important, which can reduce mortality and improve outcome. NLR may have potential predictive value in risk stratification of ischemic stroke. NLR can be obtained quickly and easily from blood cell count, which may help to select high-risk patients to start intervention in time, our results imply that this method might be applicable in AIS management.

\section{Abbreviations \\ Cl: Confidence interval; M: Mean; OR: Odds ratio; SD: Standard deviation; NLR: Neutrophil-to-lymphocyte ratio; PSI: Post-stroke infection; SAP: Stroke- associated pneumonia; UTI: Urinary tract infection (UTI); AIS: Acute ischemic stroke; IQR: Interquartile range; PCT: Procalcitonin}

\section{Acknowledgments}

We thank all patients and their families for generously consenting to use of human tissues in this research.

\section{Authors' contributions}

LYH was responsible for the concept and design of the study, data collection and analysis and the first draft of the paper and final manuscript. JW was responsible for the concept and design of the study, the data analysis and interpretation. FW was responsible for overseeing the concept and design of the study, the data analysis and interpretation, and writing the paper. LLZ, LJZ and WZ were responsible for data collection. All authors read and approved the final manuscript for publication.

\section{Funding}

This work was funded by the Health and Family Planning Commission of Chengdu (2015009), which is not involved in the database management (collection, analysis, interpretation of data) and has no access to patient information. The funding body did not participate in designing the study or writing the manuscript. The study protocol has undergone peer-review process by the funding body.

\section{Availability of data and materials}

The datasets used and/or analyzed during the current study are available from the corresponding author on reasonable request.

\section{Ethics approval and consent to participate}

We obtained ethical approval for this study from the Medical and Health Research Ethics Committee of the Second People's Hospital of Chengdu, Medical and Health Research Ethics Committee of the Yongchuan Hospital of Chongqing Medical University, Medical and Health Research Ethics Committee of Nuclear Industry 416 Hospital. The current study was carried 
out according to the Declaration of Helsinki. If the patient has consciousness disorder or aphasia, the decision cannot be made by themselves, the consent form can be signed by the patient's legal proxies. Prior to enrollment, all patients or their legal proxies will be given detailed information about the aims, scope, and possible consequences of the trial by a physician. No diagnostic or interventional procedures required for the clinical trial. Written informed consent was obtained from all study participants or their legal proxies.

\section{Consent for publication}

Not applicable.

\section{Competing interests}

The authors declare that they have no competing interests.

\section{Author details}

'Department of Neurology, The Second People's Hospital of Chengdu, Chengdu 610021, People's Republic of China. ${ }^{2}$ Department of Neurology, The Second Affiliated Hospital of Chengdu College, Nuclear Industry 416 Hospital, Chengdu 610021, People's Republic of China. ${ }^{3}$ Department of Neurology, Yongchuan Hospital, Chongqing Medical University, ChongqingChina, 610020, People's Republic of China.

\section{Received: 27 January 2020 Accepted: 27 August 2020}

\section{Published online: 01 September 2020}

\section{References}

1. Smith CJ, Bray BD, Hoffman A, Meisel A, Heuschmann PU, Wolfe CD, Tyrrell PJ, Rudd AG, Intercollegiate Stroke Working Party Group. Can a novel clinical risk score improve pneumonia prediction in acute stroke care? A UK multicenter cohort study. J Am Heart Assoc. 2015;4(1):e001307. https://doi. org/10.1161/JAHA.114.001307.

2. Ji R, Shen H, Pan Y, Wang P, Liu G, Wang Y, China National Stroke Registry Investigators. Novel risk score to predict pneumonia after acute ischemic stroke. Stroke. 2013;44(5):1303-09. https://doi.org/10.1161/STROKEAHA.111. 000598

3. Finlayson O, Kapral M, Hall R, Asllani E, Selchen D, Saposnik G, Canadian stroke network; stroke outcome research Canada (SORCan) working group. Risk factors, inpatient care, and outcomes of pneumonia after ischemic stroke. Neurology. 2011;77(14):1338-45. https://doi.org/10.1212/WNL. Ob013e31823152b1.

4. Meisel A, Smith CJ. Stroke: preventive antibiotics for stroke associated pneumonia. Nat Rev Neurol. 2015;11(12):672-3. https://doi.org/10.1038/ nrneurol.2015.220.

5. Westendorp WF, Nederkoorn PJ, Vermeij JD, Dijkgraaf MG, van de Beek D. Post-stroke infection: a systematic review and meta-analysis. BMC Neurol. 2011;11:110. https://doi.org/10.1186/1471-2377-11-110.

6. Ionita CC, Siddiqui AH, Levy El, Hopkins LN, Snyder KV, Gibbons KJ. Acute ischemic stroke and infections. J Stroke Cerebrovasc Dis. 2011;20(1):1-9. https://doi.org/10.1016/j.jstrokecerebrovasdis.2009.09.011.

7. Vermeij JD, Westendorp WF, van de Beek D, Nederkoorn PJ. Post-stroke infections and preventive antibiotics in stroke: update of clinical evidence. Int J Stroke. 2018;13(9):913-20. https://doi.org/10.1177/1747493018798557.

8. Hoffmann S, Harms H, Ulm L, Nabavi DG, Mackert BM, Schmehl I, Jungehulsing GJ, Montaner J, Bustamante A, Hermans M, Hamilton F, Göhler J, Malzahn U, Malsch C, Heuschmann PU, Meisel C, Meisel a; PREDICT investigators. Stroke-induced immunodepression and dysphagia independently PREDICT stroke-associated pneumonia - the PREDICT study. J Cereb Blood Flow Metab. 2017;37(12):3671-82. https://doi.org/10.1177/ $0271678 \times 16671964$.

9. Meisel C, Schwab JM, Prass K, Meisel A, Dirnagl U. Central nervous system injury-induced immune deficiency syndrome. Nat Rev Neurosci. 2005;6(10): 775-86. https://doi.org/10.1038/nrn1765.

10. Dirnagl U, Klehmet J, Braun JS, Harms H, Meisel C, Ziemssen T, Prass K, Meisel A.. Stroke-induced immunodepression: experimental evidence and clinical relevance. Stroke. 2007;38(2):770-3. https:// doi.https://doi.org/10. 1161/01.STR.0000251441.89665.bc.

11. Curbelo J, Luquero Bueno S, Galván-Román JM, Ortega-Gómez M, Rajas O, Fernández-Jiménez G, Vega-Piris L, Rodríguez-Salvanes F, Arnalich B, Díaz A, Costa R, de la Fuente H, Lancho Á, Suárez C, Ancochea J, Aspa J. Inflammation biomarkers in blood as mortality predictors in community- acquired pneumonia admitted patients: importance of comparison with neutrophil count percentage or neutrophil-lymphocyte ratio. PLoS One. 2017;12(3):e0173947. https://doi.org/10.1371/journal.pone.0173947.

12. de Jager CP, Wever PC, Gemen EF, Kusters R, van Gageldonk-Lafeber AB, van der Poll T, Laheij RJ.. The neutrophil-lymphocyte count ratio in patients with community-acquired pneumonia. PLoS One. 2012;7(10):e46561. https://doi.org/10.1371/journal.pone.0046561.

13. Berhane M, Melku M, Amsalu A, Enawgaw B, Getaneh Z, Asrie F. The role of neutrophil to lymphocyte count ratio in the differential diagnosis of pulmonary tuberculosis and bacterial community-acquired pneumonia: a cross-sectional study at ayder and mekelle hospitals, Ethiopia. Clin Lab. 2019;65(4). https://doi.org/10.7754/Clin.Lab.2018.180833.

14. Liu X, Shen Y, Wang H, Ge Q, Fei A, Pan S. Prognostic significance of neutrophil-to-lymphocyte ratio in patients with sepsis: a prospective observational study. Mediat Inflamm. 2016;2016:8191254. https://doi.org/10. 1155/2016/8191254.

15. Wang L, Song Q, Wang C, Wu S, Deng L, Li Y, Zheng L, Liu M Neutrophil to lymphocyte ratio predicts poor outcomes after acute ischemic stroke: A cohort study and systematic review J Neurol Sci 2019;406:116445. https://doi.org/10.1016/j.jns.2019.116445.

16. Semerano A, Strambo D, Martino G, Comi G, Filippi M, Roveri L, Bacigaluppi M. Leukocyte counts and ratios are predictive of stroke outcome and hemorrhagic complications independently of infections. Front Neurol. 2020; 11:201. https://doi.org/10.3389/fneur.2020.00201.

17. Aly M, Abdalla RN, Batra A, Shaibani A, Hurley MC, Jahromi BS, Potts MB, Ansari SA. Follow-up neutrophil-lymphocyte ratio after stroke thrombectomy is an independent biomarker of clinical outcome. J Neurointerv Surg. 2020:neurintsurg-2020-016342. https://doi.org/10.1136/ neurintsurg-2020-016342.

18. Cheng Y, Ying A, Lin Y, Yu J, Luo J, Zeng Y, Lin Y. Neutrophil-to-lymphocyte ratio, hyperglycemia, and outcomes in ischemic stroke patients treated with intravenous thrombolysis. Brain Behav. 2020;22:e01741. https://doi.org/10. 1002/brb3.1741.

19. Ying $A$, Cheng $Y$, Lin $Y, Y u$ J, Wu X, Lin Y. Dynamic increase in neutrophil levels predicts parenchymal hemorrhage and function outcome of ischemic stroke with r-tPA thrombolysis. Neurol Sci. 2020;41(8):2215-2223. https://doi.org/10.1007/s10072-020-04324-6.

20. Lux D, Alakbarzade V, Bridge L, Clark CN, Clarke B, Zhang L, Khan U, Pereira AC. The association of neutrophil-lymphocyte ratio and lymphocytemonocyte ratio with 3-month clinical outcome after mechanical thrombectomy following stroke. J Neuroinflammation. 2020;17(1):60. https://doi.org/10.1186/s12974-020-01739-y.

21. Hu Y, Huang K, Ji Z, Wang S, Bai M, Pan S, Lin Z, Wu Y. High neutrophil-tolymphocyte ratio is associated with poor clinical outcome in patients with critically ill stroke. Minerva Anestesiol. 2020. https://doi.org/10.23736/S03759393.20.14310-4. Online ahead of print.

22. Nam KW, Kim TJ, Lee JS, Kwon HM, Lee YS, Ko SB, Yoon BW. High neutrophil-to-lymphocyte ratio predicts stroke-associated pneumonia. Stroke. 2018;49(8):1886-1892. https://doi.org/10.1161/STROKEAHA.118. 021228.

23. Wang L, Guo W, Wang C, Yang X, Hao Z, Wu S, Zhang S, Wu B, Liu M. Dynamic change of neutrophil to lymphocyte ratios and infection in patients with acute ischemic stroke. Curr Neurovasc Res. 2020. https://doi.org/10.2174/1567202617666200408091131.

24. Yang $Y$, Shi $Y Z$, Zhang N, Wang S, Ungvari GS, Ng CH, Wang $Y L$, Zhao XQ, Wang YJ, Wang CX, Xiang YT. The disability rate of 5-year post-stroke and its correlation factors: a National Survey in China. PLoS One. 2016;11(11): e0165341. https://doi.org/10.1371/journal.pone.0165341.

25. Hannawi Y, Hannawi B, Rao CP, Suarez JI, Bershad EM. Strokeassociated pneumonia: major advances and obstacles. Cerebrovasc Dis. 2013;35(5): 430-43. https://doi.org/10.1159/000350199.

26. Vermeij FH, Scholte op Reimer WJ, de Man P, van Oostenbrugge RJ, Franke $\mathrm{CL}$, de Jong G, de Kort PL, Dippel DW; Netherlands Stroke Survey Investigators. Stroke-associated infection is an independent risk factor for poor outcome after acute ischemic stroke: data from the Netherlands Stroke Survey. Cerebrovasc Dis. 2009;27(5):465-471. https://doi.org/10.1159/ 000210093.

27. Yeh SJ, Huang KY, Wang TG, Chen YC, Chen CH, Tang SC, Tsai LK, Yip PK, Jeng JS. Dysphagia screening decreases pneumonia in acute stroke patients admitted to the stroke intensive care unit. J Neurol Sci. 2011; 306(1-2):3841. https://doi.org/10.1016/j.jns.2011.04.001. 
28. Saposnik G, Hill MD, O’Donnell M, Fang J, Hachinski V and Kapral MK. Variables associated with 7-day, 30-day, and 1-year fatality after ischemic stroke. Stroke. 2008;39(8):2318-24. https://doi.org/10.1161/STROKEAHA.107. 510362.

29. Khoury T, Mari A, Nseir W, Kadah A, Sbeit W, Mahamid M. Neutrophil-tolymphocyte ratio is independently associated with inflammatory activity and fibrosis grade in nonalcoholic fatty liver disease. Eur J Gastroenterol Hepatol. 2019;31(9):1110-5. https://doi.org/10.1097/MEG.0000000000001393.

30. Song M, Liu Y, Lu Z, Luo H, Peng H, Chen P. Prognostic factors for ARDS: clinical, physiological and atypical immunodeficiency. BMC Pulm Med. 2020; 20(1):102. https://doi.org/10.1186/s12890-020-1131-0.

31. Feliciano EMC, Kroenke CH, Meyerhardt JA, Prado CM, Bradshaw PT, Kwan ML, Xiao J, Alexeeff S, Corley D, Weltzien E, Castillo AL, Caan BJ. Association of Systemic Inflammation and Sarcopenia with Survival in nonmetastatic colorectal Cancer: results from the C SCANS study. JAMA Oncol. 2017;3(12): e172319. https://doi.org/10.1001/jamaoncol.2017.2319.

32. Selvaggio S, Abate A, Brugaletta G, Musso C, Di Guardo M, Di Guardo C, Vicari ESD, Romano M, Luca S, Signorelli SS. Platelet-to-lymphocyte ratio, neutrophil-to-lymphocyte ratio and monocyte-to-HDL cholesterol ratio as markers of peripheral artery disease in elderly patients. Int J Mol Med. 2020; 46(3):1210-16. https://doi.org/10.3892/ijmm.2020.4644.

33. Tao C, Wang J, Hu X, Ma J, Li H, You C. Clinical value of neutrophil to lymphocyte and platelet to lymphocyte ratio after aneurysmal subarachnoid hemorrhage. Neurocrit Care. 2017;26(3):393-401. https://doi.org/10.1007/ s12028-016-0332-0.

34. Gokhan S, Ozhasenekler A, Mansur Durgun H, Akil E, Ustundag M, Orak M. Neutrophil lymphocyte ratios in stroke subtypes and transient ischemic attack. Eur Rev Med Pharmacol Sci. 2013;17(5):653-7. PMID:23543449.

35. Jones KA, Maltby S, Plank MW, Kluge M, Nilsson M, Foster PS, Walker FR. Peripheral immune cells infiltrate into sites of secondary neurodegeneration after ischemic stroke. Brain Behav Immun. 2018;67:299-307. https://doi.org/ 10.1016/j.bbi.2017.09.006

36. Brooks SD, Spears C, Cummings C, VanGilder RL, Stinehart KR, Gutmann L, Domico J, Culp S, Carpenter J, Rai A, Barr TL. Admission neutrophillymphocyte ratio predicts 90 day outcome after endovascular stroke therapy. J Neurolntervent Surg. 2014;6(8):578-83. https://doi.org/10.1136/ neurintsurg-2013-010780

37. Saliba W, Barnett-Griness O, Elias M, Rennert G. Neutrophil to lymphocyte ratio and risk of a first episode of stroke in patients with atrial fibrillation: a cohort study. J Thromb Haemost. 2015;13(11):1971-9. https://doi.org/10. 1111/jth.13006.

38. Li L, Zhang LH, Xu WP, Hu JM. Risk assessment of ischemic stroke associated pneumonia. World J Emerg Med. 2014;5(3):209-13. https://doi. org/10.5847/wjem.j.1920-8642.2014.03.009.

39. Anrather J, ladecola C. Inflammation and stroke: an overview. Neurotherapeutics. 2016;13(4):661-70. https://doi.org/10.1007/s13311-0160483-x.

40. Lattanzi S, Brigo F, Trinka E, Cagnetti C, Di Napoli M, Silvestrini M. Neutrophil-to-lymphocyte ratio in acute cerebral hemorrhage: a system review. Transl Stroke Res. 2019;10(2):137-45. https://doi.org/10.1007/s12975018-0649-4.

41. Macrez R, Ali C, Toutirais O, Le Mauff B, Defer G, Dirnagl U, Vivien D. Stroke and the immune system: from pathophysiology to new therapeutic strategies. Lancet Neurol. 2011;10(5):471-80. https://doi.org/10.1016/S14744422(11)70066-7.

42. de Jager CP, Wever PC, Gemen EF, Kusters R, van Gageldonk Lafeber AB, van der Poll T, Laheij RJ. The neutrophil-lymphocyte count ratio in patients with community-acquired pneumonia. PLoS One. 2012;7(10):e46561. https://doi.org/10.1371/journal.pone.0046561.

43. Shim $\mathrm{R}$, Wong $\mathrm{CH}$. Ischemia, immunosuppression and infection tackling the predicaments of post-stroke complications. Int J Mol Sci. 2016;17(1):64. https://doi.org/10.3390/ijms17010064.

44. Prass K, Meisel C, Höflich C, Braun J, Halle E, Wolf T, Ruscher K, Victorov IV, Priller J, Dirnagl U, Volk HD, Meisel A. Stroke induced immunodeficiency promotes spontaneous bacterial infections and is mediated by sympathetic activation reversal by poststroke $T$ helper cell type 1-like immunostimulation. J Exp Med. 2003;198(5):725-36. https://doi.org/10.1084/ jem.20021098.

45. Walter U, Knoblich R, Steinhagen V, Donat M, Benecke R, Kloth A. Predictors of pneumonia in acute stroke patients admitted to a neurological intensive care unit. J Neurol. 2007;254(10):1323-9. https://doi.org/10.1007/s00415-007-0520-0.

\section{Publisher's Note}

Springer Nature remains neutral with regard to jurisdictional claims in published maps and institutional affiliations.

\section{Ready to submit your research? Choose BMC and benefit from:}

- fast, convenient online submission

- thorough peer review by experienced researchers in your field

- rapid publication on acceptance

- support for research data, including large and complex data types

- gold Open Access which fosters wider collaboration and increased citations

- maximum visibility for your research: over $100 \mathrm{M}$ website views per year

At $\mathrm{BMC}$, research is always in progress.

Learn more biomedcentral.com/submissions 